\title{
Microstructure and long-term corrosion of archaeological iron alloy artefacts
}

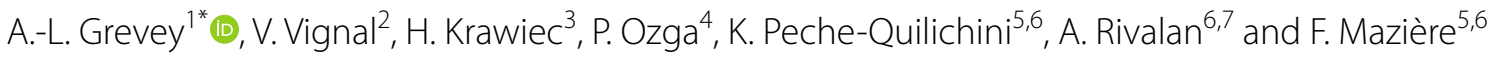

\begin{abstract}
The smithing skills of craftsmen in the western Mediterranean during the early Iron Age can be determined by studying the microstructure of oxidised iron items. While some ghost structures have already been identified in dense corrosion products, their formation has not always been explained. Four objects from southern France were analysed using optical microscopy, X-ray diffraction, micro-Raman spectroscopy and field-emission scanning electron microscopy coupled with energy dispersive spectroscopy and electron backscatter diffraction. The role of microstructure, grain boundaries, cracks, species diffusion through oxides in soil corrosion and the initial microstructure are discussed. An additional parallel degradation mechanism (graphitisation) was experimentally revealed.
\end{abstract}

Keywords: Carbon steel, SEM, X-ray diffraction, Raman spectroscopy, Oxidation

\section{Introduction}

The smithing processes of ancient craftsmen in the western Mediterranean during the first half of the early Iron Age are not well defined [1]. It is currently impossible to determine whether production was homogeneous across different geographical areas. Ascertaining whether the craftsmen selected materials with specific properties for a targeted application and whether they used heat treatments will provide some answers to this problematic.

To understand the smithing processes, it is essential to identify the microstructure of the alloy. Metallographic etching is the best way to reveal the microstructure of $\mathrm{Fe}-\mathrm{C}$ systems. This method has already been applied to a number of Portuguese items [2]. However, metallographic etching cannot be used when items are highly oxidised.

With the aim of identifying the initial microstructure of highly oxidised items, microstructural observations were performed using optical microscopy (OM) [3] and field-emission scanning electron microscopy

\footnotetext{
*Correspondence: anne-laure.grevey@orange.fr

${ }^{1}$ ASM-Archéologie des Sociétés Méditerranéennes, UMR 5140/Labex ARCHIMEDE, Programme IA ANR-11, Université Paul-Valéry Montpellier 3, Route de Mende, Site Saint-Charles, 34000 Montpellier, France Full list of author information is available at the end of the article
}

(FE-SEM) [4-7]. Based on the OM analysis, four mechanisms of formation of ghost structures were proposed [3]: (1) intergranular corrosion (corrosion propagates along ferrite grain boundaries with the formation of an oxygen-rich component in grain boundaries and an oxygen-poor component in ferrite grains), (2) inverse intergranular corrosion (grain boundaries are replaced by an oxygen-poor component, and ferrite grains by an oxygen-rich component), (3) pearlite (oxygen-rich component) corroded in preference to ferrite (oxygenpoor component) and (4) ferrite (oxygen-rich component) corroded in preference to pearlite (oxygen-poor component). FE-SEM observations at high spatial resolution revealed different ghost structures in sites with pearlite. In the first case, metallic cementite $\left(\mathrm{Fe}_{3} \mathrm{C}\right)$ was observed in the dense corrosion products [7]. It has been proposed [8] that cementite is nobler than ferrite (the pearlitic structure was composed of both) and that it acts as a cathode. Any cementite present in an initial microstructure remains intact, while any ferrite is oxidised. In the second case, the ghost structure consists of lamellar or globular pearlitic structures [4-6], in which ferrite is oxidised and cementite is transformed to pseudomorph. There is thus no electrochemical driving force for the breakdown of $\mathrm{Fe}_{3} \mathrm{C}$. While this compound can decompose to ferrite and graphite through

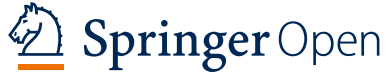

(c) The Author(s) 2020. This article is licensed under a Creative Commons Attribution 4.0 International License, which permits use, sharing. adaptation, distribution and reproduction in any medium or format, as long as you give appropriate credit to the original author(s) and the source, provide a link to the Creative Commons licence, and indicate if changes were made. The images or other third party material in this article are included in the article's Creative Commons licence, unless indicated otherwise in a credit line to the material. If material is not included in the article's Creative Commons licence and your intended use is not permitted by statutory regulation or exceeds the permitted use, you will need to obtain permission directly from the copyright holder. To view a copy of this licence, visit http://creativeco mmons.org/licenses/by/4.0/. The Creative Commons Public Domain Dedication waiver (http://creativecommons.org/publicdomain/ zero/1.0/) applies to the data made available in this article, unless otherwise stated in a credit line to the data. 
graphitisation at high temperatures [9], these conditions would not have been present during burial in the soil. Graphitisation strongly depends on temperature, pressure and time $[10,11]$. Lower temperatures require considerably more time. For example, graphitisation in carbon steel is obtained within $20 \mathrm{~h}$ at $650{ }^{\circ} \mathrm{C}$ and within $1500 \mathrm{~h}$ at $500{ }^{\circ} \mathrm{C}$ [11]. The same conclusions were drawn in [12]: the lower the temperature, the longer the time. Therefore, we can assume that graphitisation can occur at extremely low kinetics at room temperature in archaeological iron alloy artefacts. There is no experimental evidence in the literature of this degradation process in archaeological items.

Research on the corrosion processes in iron archaeological items found in soil has only emerged fairly recently $[7,8,13-24]$. It has been partly supported by the nuclear industry in relation to the storing of nuclear waste $[8,15,17]$. Studies have been conducted on archaeological items buried in different environments (atmospheric $[7,14,16,22]$, anoxic $[20]$, soil $[8,15]$ and chloride [18]). The processes of how different oxides are formed from ferrite have been expounded in the literature [16$21,25,26]$. First, $\mathrm{Fe}(\mathrm{OH})^{+}$ions are formed [26]. This ion can transform through rapid oxidation into $\mathrm{Fe}(\mathrm{OH})_{2}^{+}$ or through slow oxidation into $\mathrm{Fe}_{\mathrm{a}}^{2+} \mathrm{Fe}_{\mathrm{b}}^{3+} \mathrm{O}_{\mathrm{x}}(\mathrm{OH})_{\mathrm{y}}$. $\mathrm{Fe}(\mathrm{OH})_{2}^{+}$transforms into lepidocrocite $\gamma-\mathrm{FeO}(\mathrm{OH})$, while $\mathrm{Fe}_{\mathrm{a}}^{2+} \mathrm{Fe}_{\mathrm{b}}^{3+} \mathrm{O}_{\mathrm{x}}(\mathrm{OH})_{\mathrm{y}}$ transforms through further slow oxidation into green rust (precipitate of $\mathrm{Fe}^{2+}$ and $\mathrm{Fe}^{3+}$ ) or through rapid oxidation into magnetite $\mathrm{Fe}_{3} \mathrm{O}_{4}$ [26]. The green rust stage is followed by the formation of lepidocrocite $\gamma-\mathrm{FeO}(\mathrm{OH})$, which then transforms into a final oxide. This final oxide can be goethite $\alpha-\mathrm{FeO}(\mathrm{OH})$, magnetite $\mathrm{Fe}_{3} \mathrm{O}_{4}$ or hematite $\alpha-\mathrm{Fe}_{2} \mathrm{O}_{3}$ depending on the $\mathrm{pH}$ and potential. In addition, siderite $\left(\mathrm{FeCO}_{3}\right)$ can be found in carbonate environments [15]. While these various processes generally take place at the metal/dense product layer interface, they can also occur elsewhere (e.g. in cracks). In cases where chloride ions are present, akageneite $\beta-\mathrm{FeO}(\mathrm{OH})$ and sometimes $\beta-\mathrm{Fe}_{2}(\mathrm{OH})_{3} \mathrm{Cl}$ can be formed [18]. These are mainly found at the metal/dense product layer interface.

A key point in terms of the soil corrosion of archaeological items is the localisation of the reduction reactions. Different oxides (lepidocrocite, ferrihydrite and ferroxyhyte) can be reduced to magnetite, $\mathrm{Fe}(\mathrm{OH})_{2}$, and so on [22]. This makes the oxygen reduction reaction unnecessary and promotes oxidation processes. Using the $\mathrm{Cu}^{2+}$ / $\mathrm{Cu}^{(0)}$ couple as a marker, one study [23] has shown that an oxygen reduction reaction can occur at the surface of dense corrosion products composed of magnetite and ferrous carbonates (at the item surface as well as in any cracks). In this case, oxidation of the items may be limited by the diffusion of dissolved oxygen.
A model of the corrosion processes that occur in archaeological iron alloys found in soil has been proposed in the literature [15]. Using spatial-resolved techniques, relationships between the different oxides formed (mainly goethite $\alpha-\mathrm{FeO}\left(\mathrm{OH}\right.$ ) and magnetite $\mathrm{Fe}_{3} \mathrm{O}_{4}$ ), and some chemical parameters $(\mathrm{pH}$, presence of dissolved oxygen, presence of $\mathrm{Fe}^{2+}$ or $\mathrm{Fe}^{3+}$ ) were established. However, the authors only briefly discussed the role of cracks as a pathway for oxygen transport in the objects they examined.

This paper reports on a study of four objects excavated in southern France dating from the first half of the early Iron Age. They were selected because they still had a large metallic part and ghost structures. These objects had sustained soil corrosion in different environments (habitat and necropolis). The term "habitat" can be understood here as a residential dwelling. The term "necropolis" was preferred to that of "cemetery" because the latter has an overly restrictive Judeo-Christian connotation. Structural analyses were carried out at the macro- and microscales using OM, X-ray diffraction (XRD), micro-Raman spectroscopy and FE-SEM coupled with energy-dispersive spectroscopy (EDS) and electron backscatter diffraction (EBSD). The corrosion mechanisms identified are discussed below. Other parallel degradation mechanisms were also examined.

\section{Method}

\section{Materials and sample preparation}

Four objects were studied. Two of the objects (a shaft named object \#1 and a slab named object \#2) were excavated from a protohistoric habitat located in Corsica (Serra-di-Scopamène/Sorbollano) [27]. The first was dated to between the 8th and 7th centuries BCE and came from an open space named "Rampe G". The second, which dated to the 7th century BCE, came from a house named "Structure 1". These two objects were excavated in 2014 (object \#1) and 2009 (object \#2) in granite soil (pH around 6), and both were stored in minigrip in a standard reserve without special treatment. The other two objects were excavated from two protohistoric necropolises in southern France. One, object \#3, was a knife dated to between the second and third quarter of the 7th century BCE (grave 91, necropolis of La Rouquette, Puisserguier, Herault). Object \#3 was excavated between 2003 and 2004. It was found in an ossuary vase and had therefore been in contact with burned human bones (all protected by a ceramic cover). The terrain was clay and slightly acidic. After stabilisation (same procedure as that used in [28]), it was packaged in a minigrip accompanied by Propasec desiccant bags (from Propagroup) and stored in a reserve with controlled atmosphere. The other, object \#4, was a knife dated to between the 7th and early 
6th centuries BCE (grave 991, necropolis of Le Causse, Labruguière, Tarn). Object \#4 was excavated in 2010. It was located on a limestone bedrock (basic medium) of the burial grave and covered with silty clay. It was packaged in a minigrip and stored in a standard reserve without special treatment.

These four objects were prepared for the XRD, microRaman, FE-SEM/EDS/EBSD and OM analyses. They were first cut using a diamond band saw, as shown in Fig. 1a1, b1, c1 and d1. The cross-section surfaces (Fig. 1a2, a3, b2, b3, c2, c3 and d2, d3) were then mechanically ground down to 4000 grit using silicon carbide $(\mathrm{SiC})$ papers and polished with diamond pastes (down to $1 \mu \mathrm{m}$ ). The specimens were ultrasonically cleaned in acetone between each of these steps. For the EBSD measurements, vibratory polishing was carried out on the cross sections of objects \#1, \#2 and \#4.

\section{Surface observations}

Optical images of the cross-section surfaces were recorded at the macroscale using a Nikon Eclipse LV150A upright metallurgical microscope. These optical images were assembled to produce two-dimensional reconstructions of the surfaces.

Surface observations at the microscale were performed using FE-SEM (JEOL JSM-7600F) coupled with EDS. The microscope operated at $15 \mathrm{kV}$ and with a probe current of $3 \mathrm{nA}$. The working distance was set at $15 \mathrm{~mm}$. Images were acquired in low angle backscatter electron image (LABE) mode. This detector is capable of producing qualitative compositional images with a very high degree of atomic number contrast.

The grain orientation was determined using FE-SEM coupled with the TSL EDAX OIM XM4 electron backscattered diffraction system. EBSD measurements were made on a surface area of $2.8 \times 3.7 \mathrm{~mm}^{2}$ with a step of $4 \mu \mathrm{m}$ and an integration time of $23 \mathrm{~ms}$ per point.

\section{X-ray diffraction measurements}

XRD analysis was performed using $\mathrm{CuK} \alpha(\lambda=1.54 \AA)$ as the radiation source. Measurements were carried out with a Bruker D8-A25-Advance diffractometer and a LynxEye detector. XRD diffractograms were fitted using the Topas software package and the Rietveld method (structural model) [29]. The XRD spot size was set at $2 \mathrm{~cm}^{2}$. Hence, the surface of the four objects was completely irradiated over the full angular range $(2 \theta$ in the range of $15-100^{\circ}$ ).

\section{Micro-Raman spectroscopy measurements}

Micro-Raman spectra were taken in backscattering geometry using a Renishaw inVia Raman microscope $(100 \times$ objective lens and numerical aperture $\mathrm{NA}=0.85$, spatial resolution $1 \mu \mathrm{m}$ ) with $633 \mathrm{~nm} \mathrm{HeNe}$ excitation laser, $1 \mathrm{~s}$ exposure time, 1000 accumulations and laser power reduced by filters to $700 \mu \mathrm{W}$ to avoid sample degradation due to heating effects. When the laser power is too high, lepidocrocite, siderite, magnetite, maghemite, ferrihydrite and wustite can form by oxidation [30]. A Peltier-cooled CCD matrix detector with a resolution of $1.3 \mathrm{~cm}^{-1}$ (diffraction gratings of 1800 grooves $\mathrm{mm}^{-1}$ ) was used for detection. The spectra were collected in fast mode at a fixed position of grating according to wavenumber ranges: (i) $50-1300 \mathrm{~cm}^{-1}$ (oxide bands range); (ii) $900-2000 \mathrm{~cm}^{-1}$ (the rest oxide bands, graphite D and G bands and amorphous carbon band range); (iii) 2500 $3250 \mathrm{~cm}^{-1}$ (graphite 2D band). The spectrum model profile was determined by fitting each fragment of spectrum following background correction with a pseudo-Voigt profile (linear combination of the Gaussian and Lorentzian curves) using Renishaw Wire ver. 3.4 software. Graphite 2D band is missing in spectra. 2D band is very sensitive to the stacking order of the graphene sp2 layers in graphite along the $\mathrm{c}$-axis, which is what indicates the weakly oriented graphite present in analysed samples. Hence, the spectra in 2D range are not presented.

\section{Results and discussion}

\section{Identification of corrosion products}

Objects \#1, \#2 and \#4 contained a large metallic part at each of their centres $(\sim 13 \%$ of the total surface area of the cross section for object \#2, and $\sim 27 \%$ for objects \#1 and \#4), the hatched regions in Fig. 1a2, b2, d2. For example, the metallic part of object \#2 extended over a surface area of $\sim 1.8 \times \sim 0.2 \mathrm{~cm}^{2}$. By contrast, object \#3 contained only very small metallic particles $(<1 \%$ of the total surface area of the cross section): the largest particle was around $100 \times 300 \mu \mathrm{m}^{2}$ ). In the objects' external zones, dense corrosion products were observed, corresponding to the grey regions in Fig. 1a3, b3, c3, d3. Figure 2 shows that different phases (associated with different colours in optical and FE-SEM images in LABE mode) existed in these dense corrosion products.

A quantitative phase analysis was then performed by XRD. The XRD diffractograms obtained were complex (numerous peaks), making it difficult to identify all the phases (Fig. 3). This confirmed that all the oxides were mixed, leading to complex microstructures. Phase identification was also performed using micro-Raman spectroscopy. This technique offers some advantages when compared with XRD. It allows the measurement of both crystalline and amorphous compounds as well as the analysis of single sites. It is therefore easier to deconvolute the micro-Raman spectra (fewer compounds present). Figure 4 and Additional files 1 and 2 show the micro-Raman spectra in specific sites for objects \#1, \#2, 

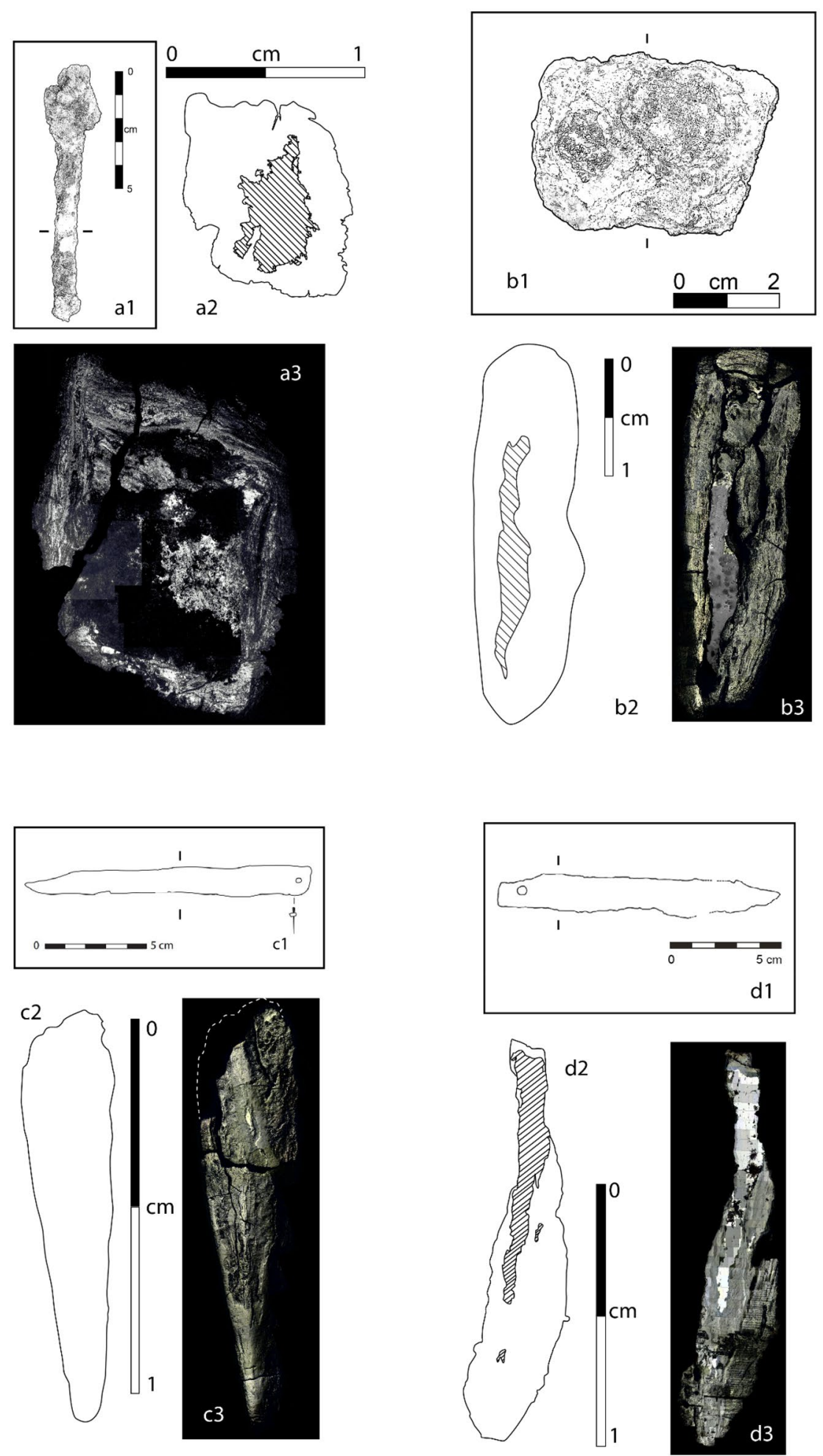

Fig. 1 Location of sampling sites where observations and analyses were performed. 1 =drawing of the object, $2=$ schematic representation of the cross section (hatched regions: metallic iron), 3 = optical images: grey regions: dense corrosion products. a Object \#1, b object \#2, c object \#3 and d object \#4. On the (1) drawings, the hatched drawing represents the metal part 


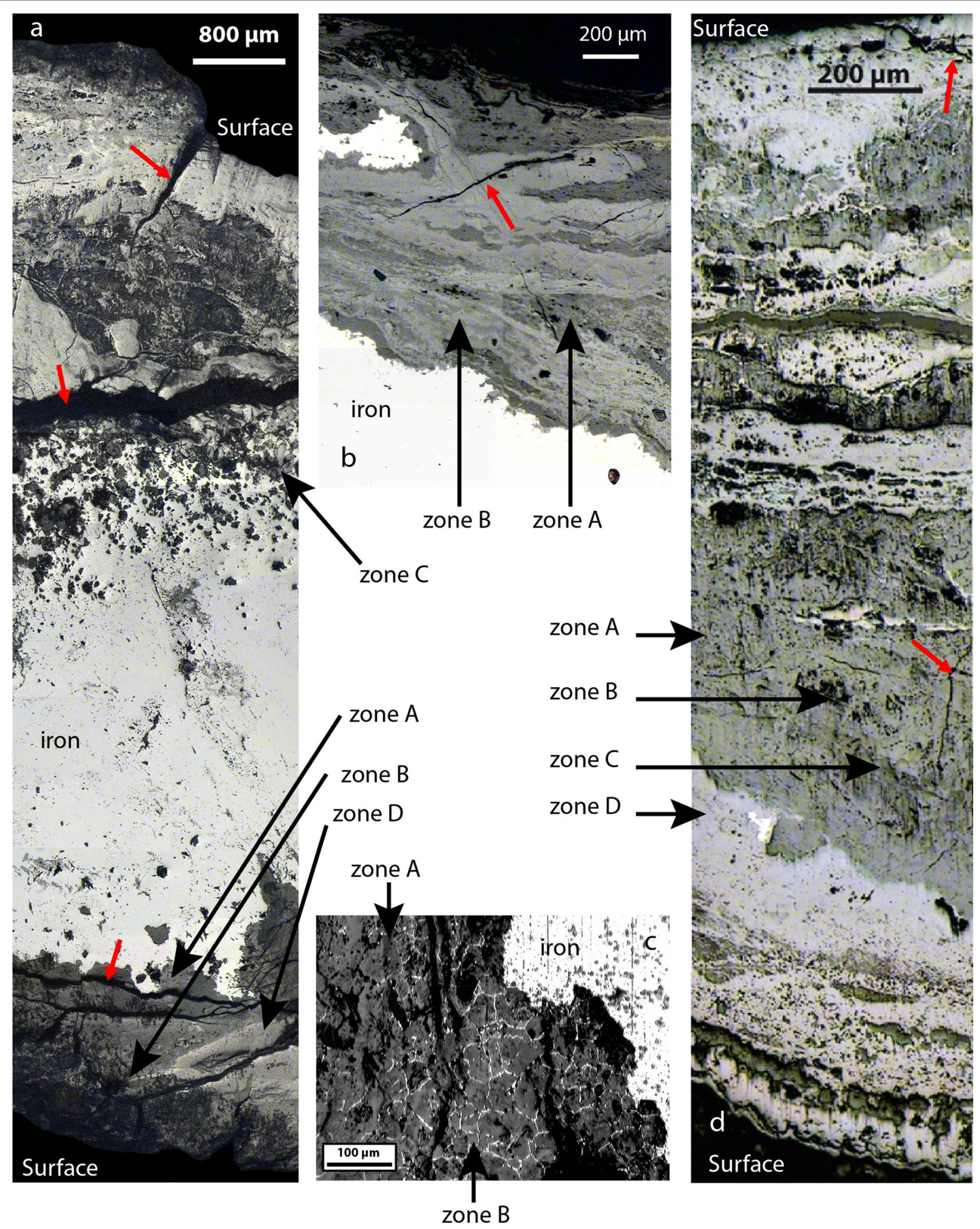

Fig. 2 Optical images of the dense corrosion products (oxidised parts) of a object \#1, $\mathbf{b}$ object \#4, c object \#2, d object \#3. Only the main oxide in the different zones is indicated here. A complete compilation of the oxides present are indicated in Fig. 4 (object \#1), Fig. 5 (objects \#2 and \#4) and Fig. 6 (object \#3). The red arrows show the cracks 

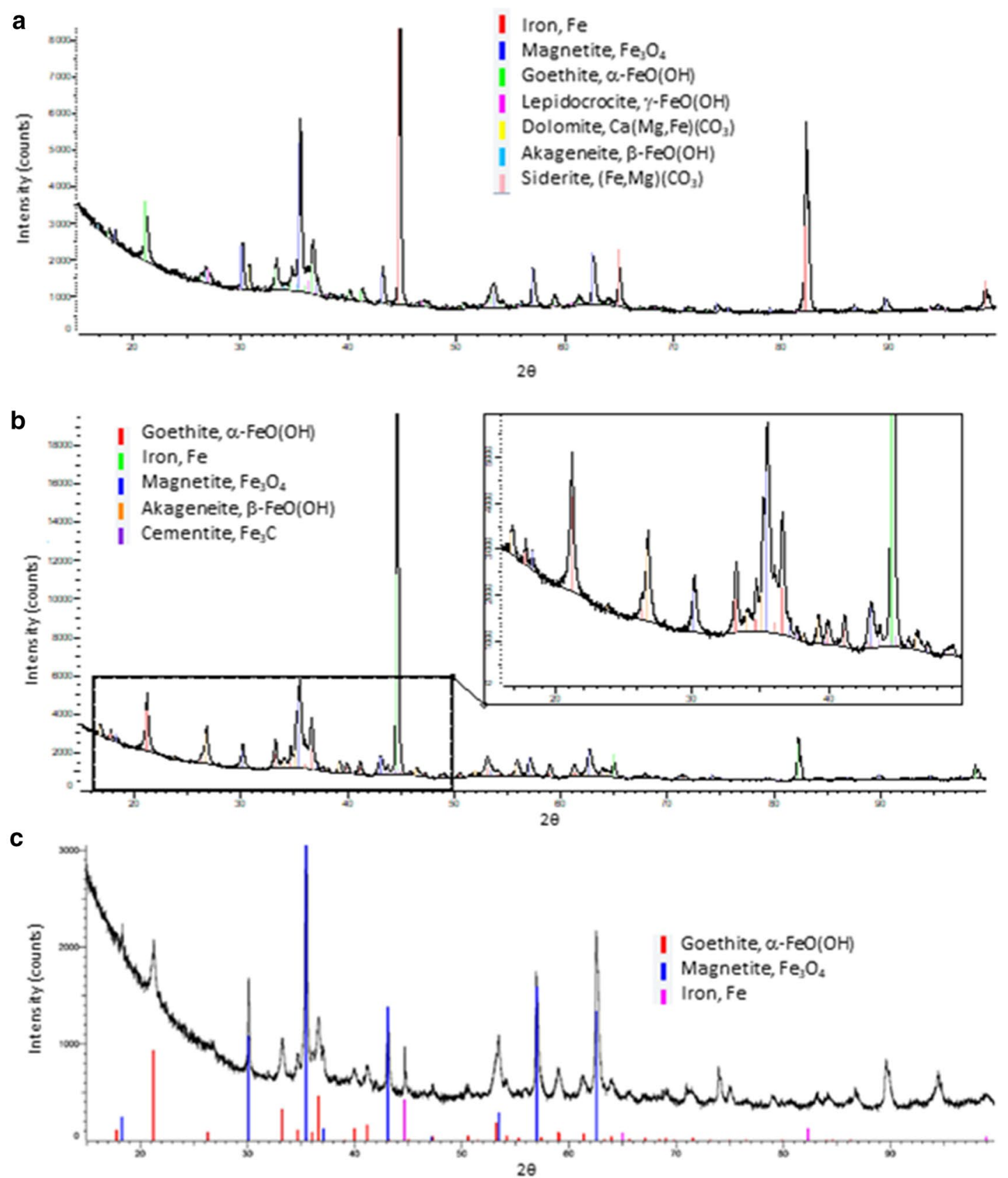

d

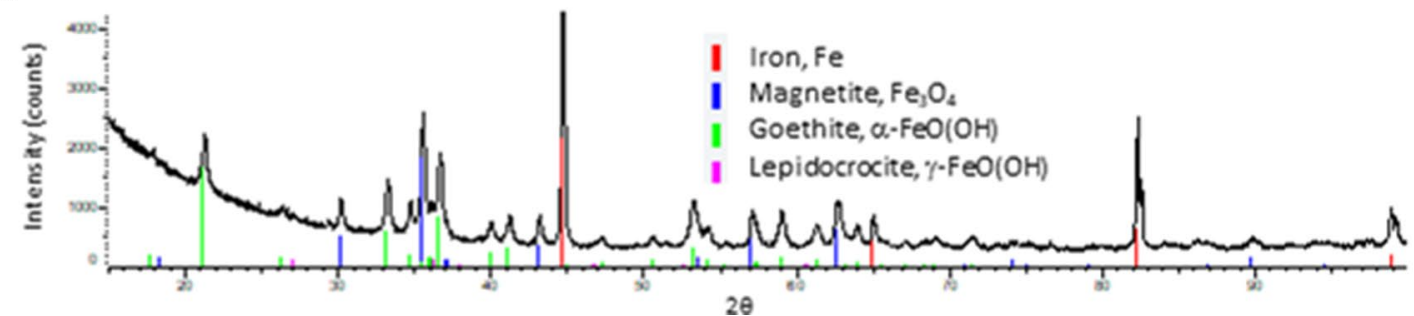

Fig. 3 XRD diffractograms of the four objects: a object \#1, b object \#2, c object \#3 and $\mathbf{d}$ object \#4 

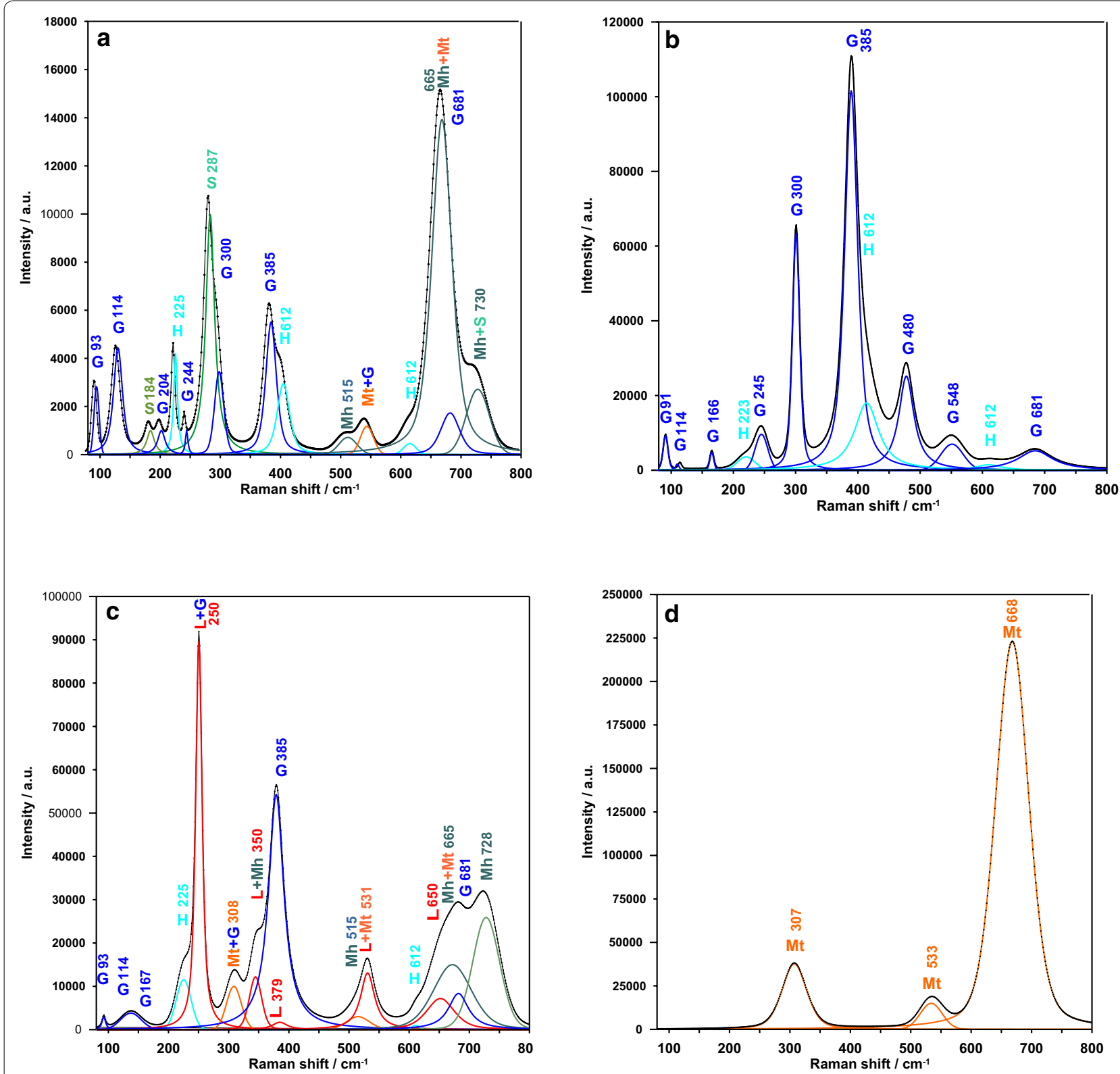

Fig. 4 Raman spectra results for object \#1: a zone A, b zone B, c zone C and $\mathbf{d}$ zone D. The zones are indicated in Fig. 2. G: goethite, H: hematite, Mt: magnetite, L: lepidocrocite, Mh: maghemite, S: siderite

$\# 3$ and \#4. For objects \#2 and \#4, the micro-Raman measurements were performed in both the dark grey (zone A in Fig. 2 and Additional file 1) and the light grey layers (zone B in Fig. 2 and Additional file 1). For objects \#1 and \#3, the micro-Raman measurements were carried out in zones A, B, C and D, as shown in Figs. 2 and 4, and Additional file 2. These zones (A-D) were selected because they are characterised by different levels of grey on the FE-SEM images in LABE mode (see "Method" section) and therefore by different levels of different chemical contrasts (composition, stoichiometry). The micro-Raman spectra were deconvoluted into individual bands using data from the literature: akageneite $\beta$ - $\mathrm{FeO}(\mathrm{OH})$ [24], ferrihydrite $\mathrm{Fe}_{5} \mathrm{HO}_{8} * 4 \mathrm{H}_{2} \mathrm{O}$ [25], goethite $\alpha-\mathrm{FeO}(\mathrm{OH})[31,32]$, hematite $\alpha-\mathrm{Fe}_{2} \mathrm{O}_{3}[24,30,31]$, lepidocrocite $\gamma-\mathrm{FeO}(\mathrm{OH})$ [31], maghemite $\gamma-\mathrm{Fe}_{2} \mathrm{O}_{3}$ [30, 33], magnetite $\mathrm{Fe}_{3} \mathrm{O}_{4}[30,34,35]$ and siderite $\mathrm{FeCO}_{3}$ [30].

The quantitative phase analysis by XRD revealed that two main oxides were present, namely goethite $(\alpha-\mathrm{FeO}(\mathrm{OH}))$ and magnetite $\left(\mathrm{Fe}_{3} \mathrm{O}_{4}\right) /$ maghemite 
$\left(\gamma-\mathrm{Fe}_{2} \mathrm{O}_{3}\right)$, as reported in Table 1. It is not possible to distinguish $\mathrm{Fe}_{3} \mathrm{O}_{4}$ from $\gamma-\mathrm{Fe}_{2} \mathrm{O}_{3}$ using XRD. Phase identification by micro-Raman showed that maghemite was only present in object \#1. In the other three objects, both compounds $\left(\mathrm{Fe}_{3} \mathrm{O}_{4}\right.$ and $\left.\gamma-\mathrm{Fe}_{2} \mathrm{O}_{3}\right)$ were present. This quantitative phase analysis by XRD also revealed that a large quantity of akaganeite was present in object \#2.

The main XRD peaks of lepidocrocite (at $2 \theta=27.04^{\circ}$ ) and akageneite (at $\left.2 \theta=26.74^{\circ}\right)$ were very close $(\Delta 2 \theta$ of $\left.0.3^{\circ}\right)$. In addition, the second peak of lepidocrocite was located between the peaks associated with the two main compounds (goethite and magnetite). With the exception of object \#2 (large amount of akageneite), it was therefore difficult to distinguish the two oxides (lepidocrocite and akageneite) and to give accurate quantities. This explains why there was no real correspondence between the XRD and micro-Raman results for these two compounds (Table 1). The micro-Raman measurements indicated that lepidocrocite was present in objects \#1, \#2 and $\# 3$ and that akageneite was present in objects \#2 and \#3.

Therefore, the XRD and micro-Raman measurements revealed that dense corrosion products formed during the soil corrosion of objects are systematically composed of goethite, magnetite (two main compounds) and lepidocrocite (small amount). Akaganeite (large amount in object \#2), maghemite and ferrihydrite are also found in some objects. Hematite and siderite were only detected in object \#1 (small amount) in this study. This finding confirms that goethite and magnetite are end products of the corrosion reaction and are thermodynamically stable $[22,23]$.

\section{Microstructure of corrosion products}

The FE-SEM/EDS analysis of the dark grey layers visible in Fig. 2d yielded 62.1 at.\% O (from the stoichiometric calculation) and 37.9 at.\% Fe and of the light grey layers visible in Fig. 2 d revealed 52.5 at.\% $\mathrm{O}$ and 47.5 at.\% Fe. The FE-SEM/EDS analysis therefore indicated that the dark grey and light grey layers corresponded to goethite (in theory: 67 at.\% $\mathrm{O}$ and 33 at.\% $\mathrm{Fe}$ ) and magnetite (in theory: 57 at.\% O and 43 at.\% Fe), respectively. The micro-Raman and XRD analyses showed that other compounds could be present in these two layers. A stoichiometric analysis could not therefore be performed.

Low spatial resolution observations (at the macroscale) of the four objects \#1-\#4 revealed the existence of successive layers composed mainly of goethite and magnetite (Fig. 2). At the macroscale, the interfaces between the successive layers of magnetite and goethite seemed to be relatively regular. This marbling is discussed below. High spatial resolution observations indicated that the oxides (goethite and magnetite) were often mixed, with the mix composed of different percentages of each oxide (Fig. 2b-d). This indicates that corrosion mechanisms are complex and that they may depend on the object microstructure, the presence of cracks, and so on.

\section{Corrosion mechanisms in the presence of soil water}

According to the literature ("Introduction" section), corrosion mechanisms result in the formation of $\alpha-\mathrm{FeO}(\mathrm{OH})$ and $\mathrm{Fe}_{3} \mathrm{O}_{4}$ at the metallic surface. This is consistent with the XRD and micro-Raman results reported in Table 1, which show that the main oxides present in the objects were $\alpha-\mathrm{FeO}(\mathrm{OH})$ and $\mathrm{Fe}_{3} \mathrm{O}_{4}$. Only a small quantity of $\gamma-\mathrm{FeO}(\mathrm{OH})$ was detected by XRD, suggesting that it had not yet transformed. At this stage, no crack initiates, and corrosion propagates uniformly along a front. This corrosion mechanism has already been described in the literature [15].

As corrosion had proceeded in the four objects, the formation of numerous dense oxides had resulted in the initiation and propagation of a number of cracks, as shown in Figs. 2 and 5a. These cracks had propagated in all directions (i.e. there were no preferential directions). As the cracks had emerged at the surface of these objects, they had promoted the propagation of soil water

Table 1 Identification of compounds found in the dense layers by means of XRD and micro-Raman spectroscopy ( $\mathrm{X}=$ compound is present)

\begin{tabular}{|c|c|c|c|c|c|c|c|c|c|}
\hline & & $\begin{array}{l}\text { Magnetite/ } \\
\text { Maghemite } \\
\mathrm{Fe}_{3} \mathrm{O}_{4} / \mathrm{Y}-\mathrm{Fe}_{2} \mathrm{O}_{3}\end{array}$ & $\begin{array}{l}\text { Goethite } \\
\text { a-FeO(OH) }\end{array}$ & $\begin{array}{l}\text { Lepidocrocite } \\
\text { Y-FeO(OH) }\end{array}$ & $\begin{array}{l}\text { Akaganeite } \\
\beta-\mathrm{FeO}(\mathrm{OH}, \mathrm{Cl})\end{array}$ & $\begin{array}{l}\text { Hematite } \\
\mathrm{a}-\mathrm{Fe}_{2} \mathrm{O}_{3}\end{array}$ & $\begin{array}{l}\text { Siderite } \\
\mathrm{FeCO}_{3}\end{array}$ & $\begin{array}{l}\text { Ferrite } \\
\text { Fe }\end{array}$ & $\begin{array}{l}\text { Cementite } \\
\mathrm{Fe}_{3} \mathrm{C}\end{array}$ \\
\hline \multirow[t]{2}{*}{ Object \#1 } & XRD (phase \%) & 18.9 & 25.7 & 6 & 5.5 & / & 1.7 & 39.4 & / \\
\hline & Raman & $x$ & X & $x$ & / & $x$ & $x$ & / & / \\
\hline \multirow[t]{2}{*}{ Object \#2 } & XRD (phase \%) & 21.6 & 34 & / & 21.2 & / & / & 19.7 & 3.5 \\
\hline & Raman & X & X & $x$ & $x$ & / & / & / & / \\
\hline \multirow[t]{2}{*}{ Object \#3 } & XRD (phase \%) & 48.8 & 50.6 & / & / & / & / & 0.6 & / \\
\hline & Raman & X & X & $x$ & $x$ & / & / & / & / \\
\hline \multirow[t]{2}{*}{ Object \#4 } & XRD (phase \%) & 19.4 & 51.9 & 1.9 & / & / & / & 26.8 & / \\
\hline & Raman & $x$ & $x$ & / & / & / & / & / & / \\
\hline
\end{tabular}



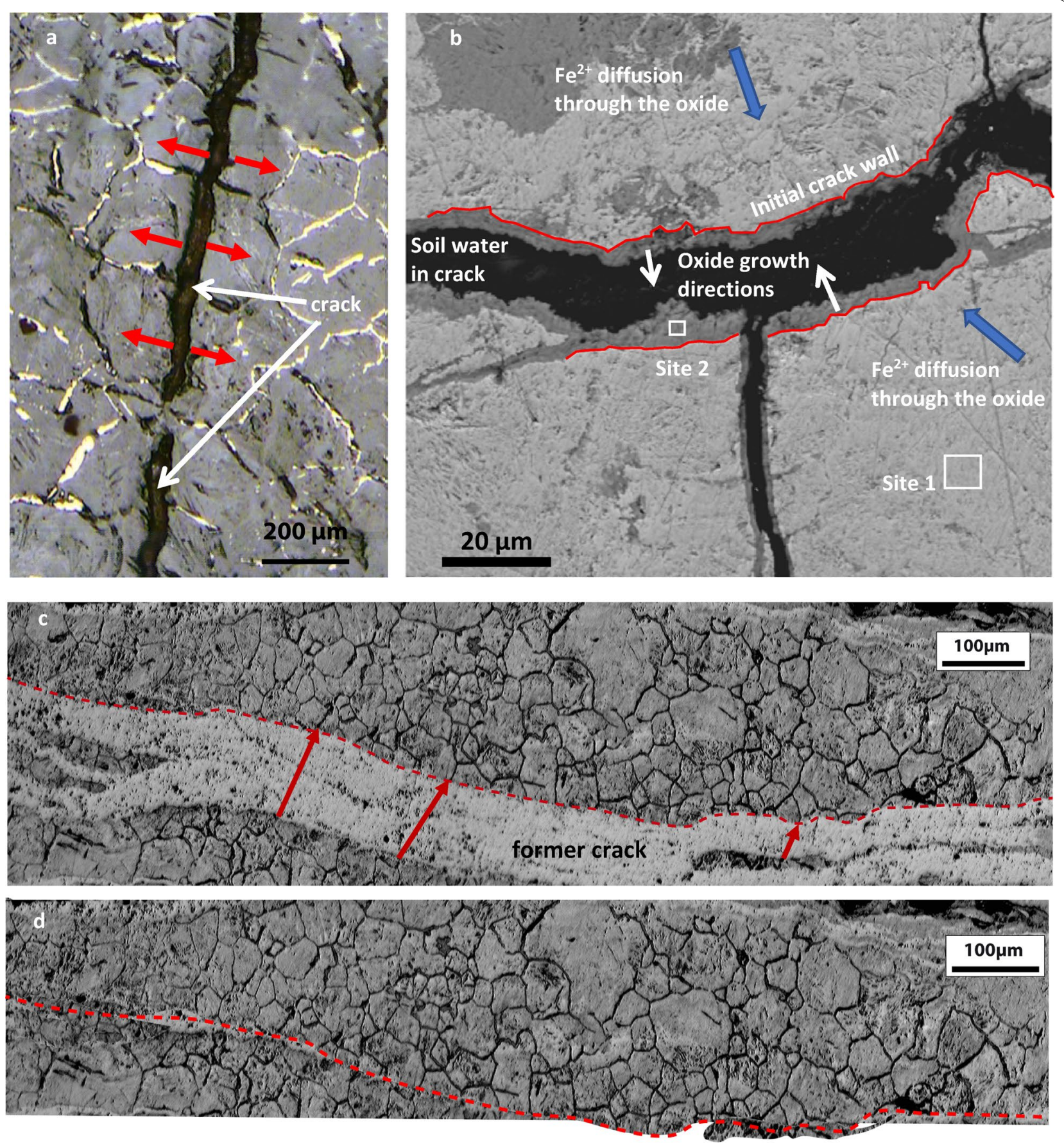

Fig. 5 FE-SEM (b) and optical (a, c, d) micrographs of sites containing cracks in objects \#3 (b) and \#2 (a, c, d). a Shows initial crack (empty), b shows crack filling process, $\mathbf{c}$ shows marbling witness of former crack, $\mathbf{d}$ shows assembly of the two initial crack walls from (c) leading to the reconstruction of the microstructure

(with dissolved oxygen) inside them. At the same time as the cracks were propagating, an outward diffusion of $\mathrm{Fe}^{2+}$ had occurred through dense oxides, from the metallic parts to the free surfaces (including crack walls). This $\mathrm{Fe}^{2+}$ had then oxidised, and a new oxide had grown. The outward diffusion of $\mathrm{Fe}^{2+}$ had been promoted through oxides containing a high density of defects (vacancies, dislocations, etc.). This was the case with the non-stoechiometric oxides, as in site 1 in Fig. 5b. The FE-SEM/ EDS analysis of site 1 yielded 44.5 at.\% $\mathrm{O}$ and 55.5 at.\% 

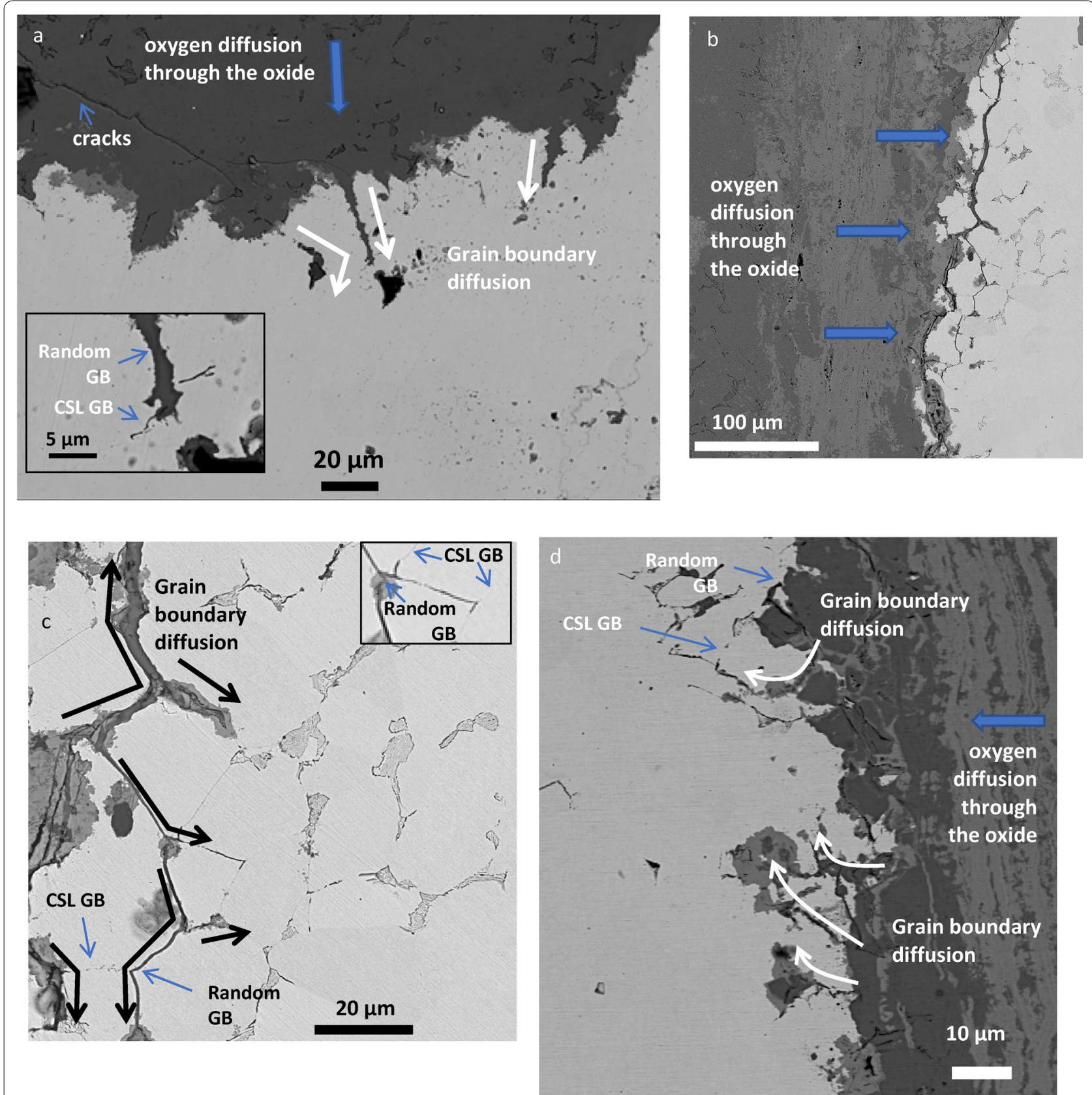

Fig. 6 FE-SEM/EDS micrographs of intergranular oxidation observed in a object \#1, b, c object \#4 and $\mathbf{d}$ object \#3. Random GB= random grain boundaries; CSL GB $=$ lattice grain boundaries

Fe. This corresponds to a non-stoichiometric compound. The oxide that had formed in the crack (site 2 in Fig. $5 \mathrm{~b}$ ) was $\mathrm{Fe}_{3} \mathrm{O}_{4}$ (FE-SEM/EDS analysis: 60.1 at.\% $\mathrm{O}$ and 39.9 at.\% $\mathrm{Fe}$ ). As the oxide had grown, the crack diameter had decreased. At the end of this process, the crack had become completely obstructed by the oxide (Fig. 5c) and soil water was no longer able to flow through it. The ghost structures on both sides of the crack fitted together perfectly (Fig. 5d). This confirmed that a new oxide had been formed in the crack due to the presence of soil water and that the ghost structure on both sides of the crack had not been destroyed by this process.

Taking into account the influence of a high density of cracks in the corrosion mechanisms, the dense corrosion products were composed of a mixture of the different oxides, as revealed by the high spatial resolution observations (Fig. 2b-d). 


\section{Intergranular oxidation}

Intergranular oxidation was often observed in objects $\# 1$, \#3 and \#4 (Fig. 6). A high density of cementite was located at the grain boundaries of object \#2. This particular case is investigated in "Oxidation of sites containing pearlite and graphitisation of cementite" section. The supply of oxygen to the metallic parts in the objects had been controlled by inward diffusion through the dense oxides. Oxygen had penetrated the metallic grains (lattice diffusion) and the grain boundaries (grain boundary diffusion). As shown in Fig. 6, grain boundary diffusion occurs at a faster rate than lattice diffusion.

Grain boundary diffusion depends on the nature of the grain boundary. Grain boundaries of $3 \leq \Sigma \leq 29$ are regarded as a coincidence site lattice (CSL) grain boundary (where $\Sigma$ is the coincidence index), and those of $\Sigma>29$ are regarded as a random grain boundary [36]. The EBSD measurements carried out on object \#1 showed that most of the grain boundaries were random grain boundaries (shown in black in Fig. 7a). However, coincidence site lattice (CSL) grain boundaries (shown in blue in Fig. 7a) were also found. These were uniformly distributed in the metal. The low energies associated with these grain boundaries do not favour fast diffusion. It was therefore expected that strong oxidation would be observed along random grains (shown by the white arrows in Fig. 6). Once a CSL grain boundary is reached, intergranular oxidation stops (see inserted image in Fig. 6a and d). Surface observations showed that oxygen had penetrated along grain boundaries to a maximum depth of $20 \mu \mathrm{m}$ (object \#4 (Fig. 6b).

The presence of dislocations in the grains can increase lattice diffusion rates [37]. The EBSD measurements carried out on objects \#1 and \#4 showed that $50 \%$ of the grains had a grain orientation spread greater than $4^{\circ}$ (Fig. 7b for object \#1), indicating that the density of geometrically necessary dislocations was high in those grains. Oxygen penetration in grains with a high grain orientation spread (GOS) value had therefore been promoted.

\section{Oxidation of sites containing pearlite and graphitisation of cementite}

Cementite with a lamellar structure was observed in the dense oxides formed in objects \#1-\#4 (objects \#2 and \#4 in Fig. 8). This had initially been pearlite (the ferrite had been preferentially oxidised due to an inward diffusion of oxygen). It is a well-established fact [8] that cementite is nobler than ferrite. When oxidation of the surrounding ferrite had been complete, the cementite had undergone

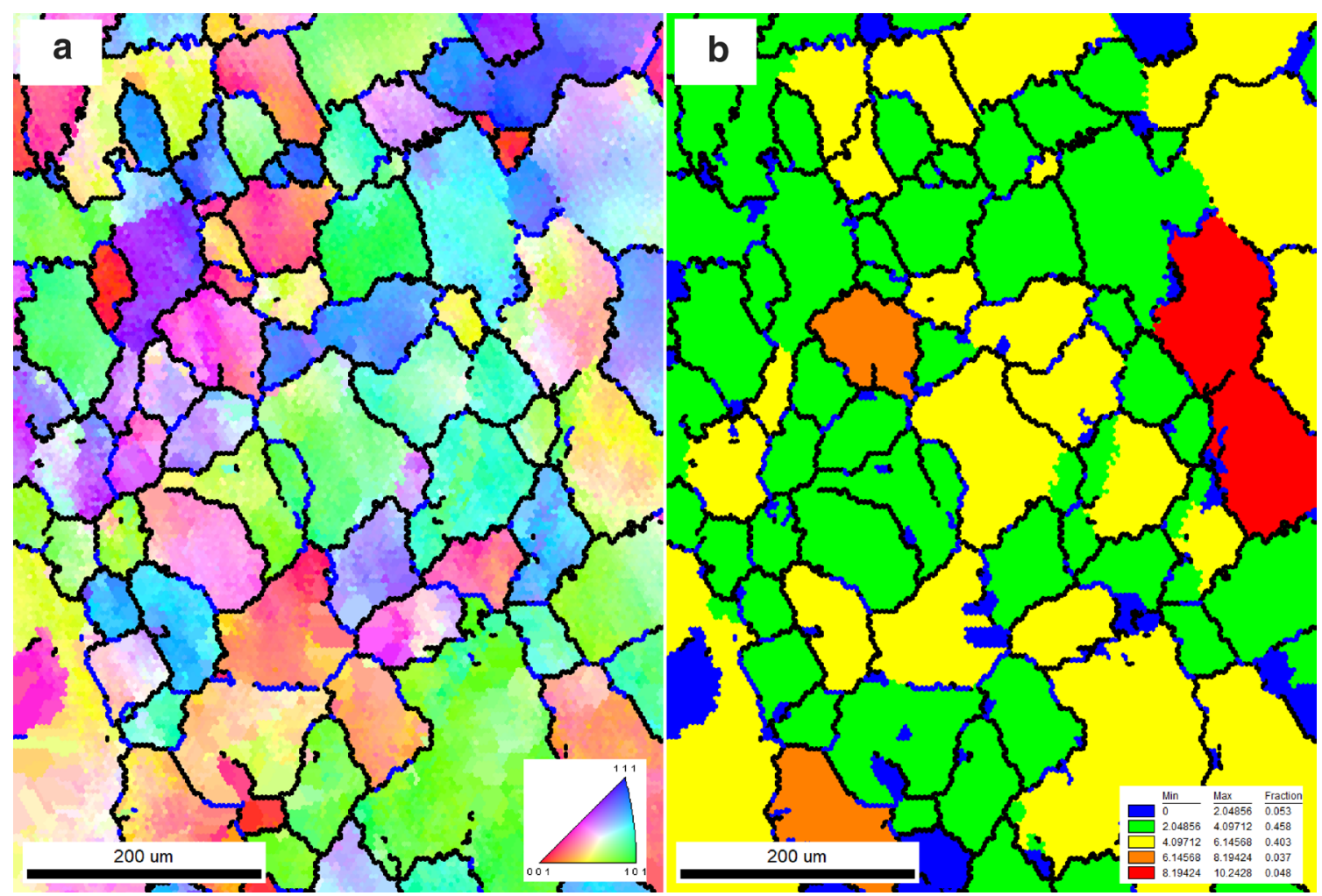

Fig. 7 a Inverse pole figure and $\mathbf{b}$ GOS maps derived from the EBSD measurements on object \#1. Grain boundaries are also represented: Random grain boundaries (shown in black) and CSL grain boundaries (shown in blue) 

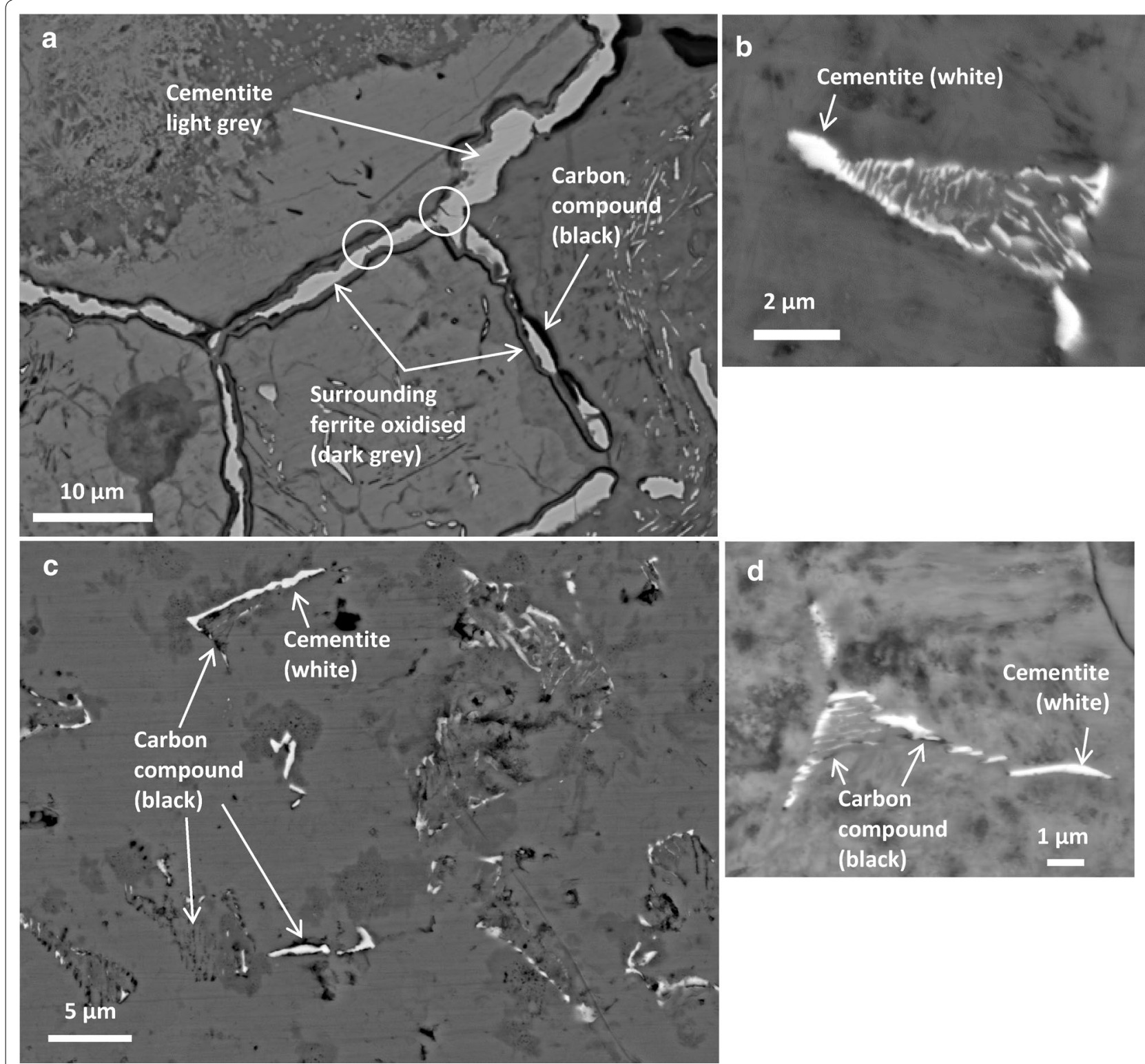

Fig. 8 FE-SEM images (back-scattered electrons mode) of cementite in the dense oxides in object \#2 (a) and object \#4 (b)

substantial deformation, leading to the formation of microcracks (shown as circles in Fig. 8a).

The distribution of carbon, oxygen and iron in a site containing cementite embedded in the dense oxides is shown in Fig. 9a-d for a hypereutectoid object (object \#2) and in Fig. 9e-h for a hypoeutectoid object (object \#1). This was obtained by means of FE-SEM/EDS. Sites 1 correspond to cementite that had not yet been transformed ( $\mathrm{Fe}$ and $\mathrm{C}$ were mainly found). In sites 2 , only carbon was significantly detected. The micro-Raman analysis showed the formation of graphite and amorphous carbon (Fig. 10). Both these elements were mixed with oxides. Therefore, the FE-SEM/EDS and microRaman results revealed that graphitisation had occurred in objects \#1-\#4. The micro-Raman spectra were deconvoluted into individual bands using data from the literature, namely carbon graphite and amorphous carbon $[38,39]$. The FE-SEM/EDS images also showed that graphitisation had started from the interface between the cementite and the dense oxides and had propagated into the cementite.

Only $\mathrm{Fe}_{3} \mathrm{C}$ (and not graphite) was observed in the metallic parts of objects \#1-\#4. This means that the graphite observed in the corroded parts could not have 

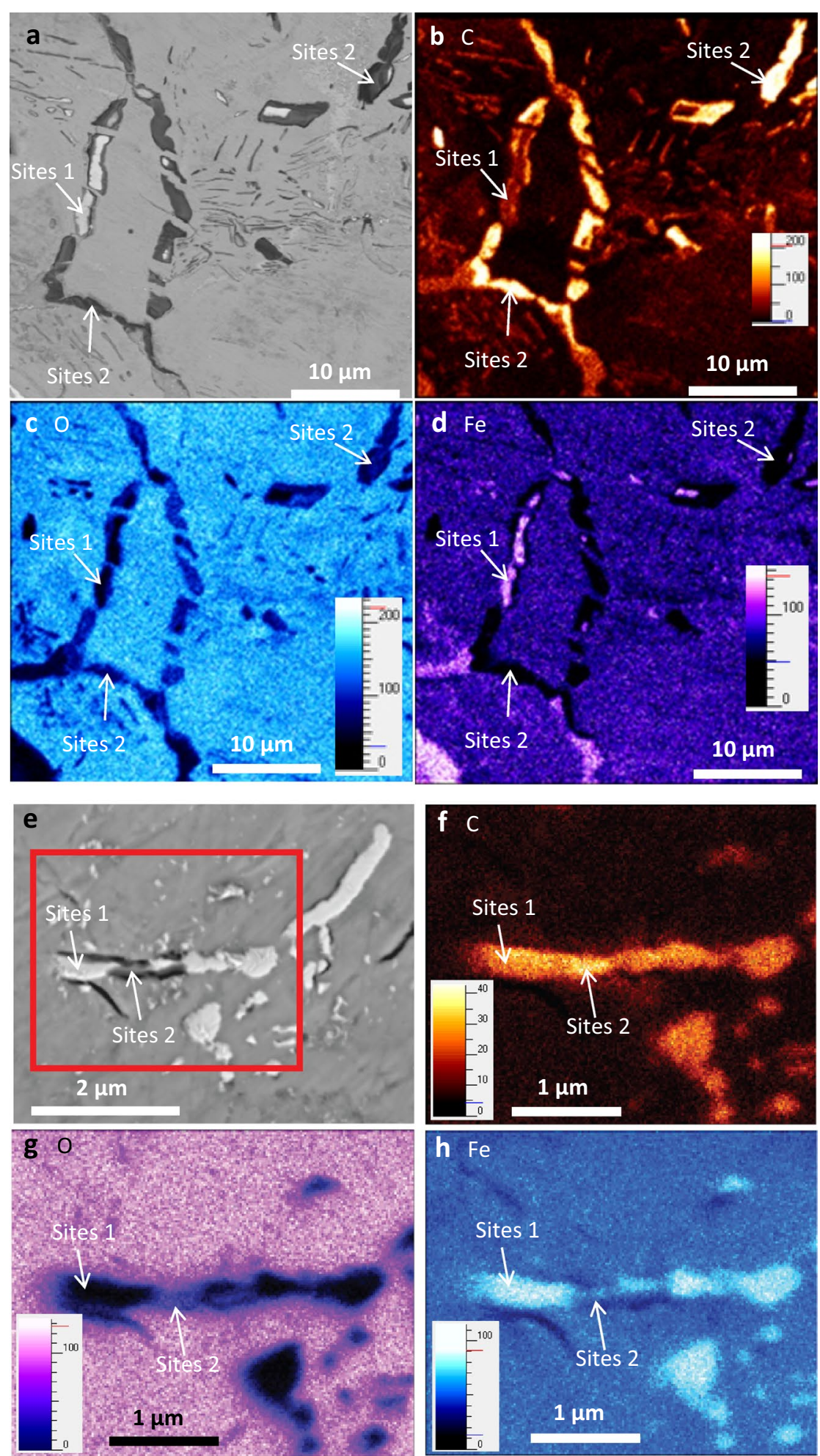

Fig. 9 a-d FE-SEM/EDS elemental mapping of a site containing pearlite embedded in the dense oxides in $\mathbf{a}-\mathbf{d}$ object \#2 and $\mathbf{e}-\mathbf{h}$ object \#1 

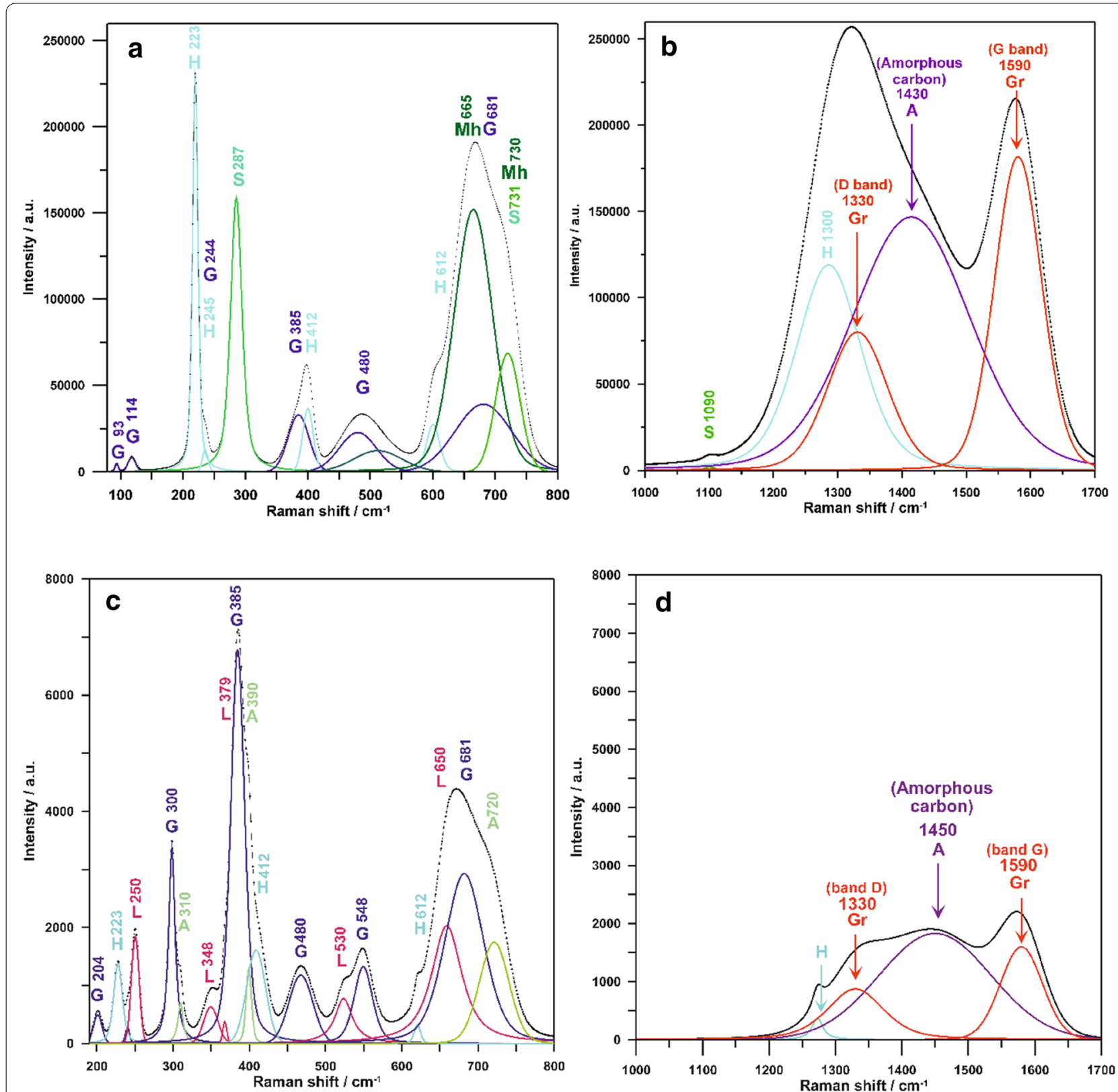

Fig. 10 a, b Raman spectra of the black boundaries (sites 2 in Fig. 9a-d). c, d Raman spectra of the white boundaries (sites 1 in Fig. 9a-d). G: goethite, H: hematite, Mh: maghemite, S: siderite, L: lepidocrocite, Gr: graphite, A: amorphous carbon (black line and points=experimental spectrum; dark blue, light blue, dark green, light green, red and purple lines= models spectrum)

resulted from graphitisation occurring during the elaboration process at high temperatures. This happens during burial in soil for a very long period. As already discussed in "Introduction" section, we assumed that graphitisation can occur at extremely low kinetics at room temperature. This would require considerable time. This is compatible with the fact that these objects were buried for at least 2600 years (corresponding to nearly 23 millions $\mathrm{h}$ ).

\section{Discussion of initial microstructure}

In the absence of large metallic parts in archaeological iron alloy objects, the only way of determining their initial structure is to map the ghost structures (with graphite), non-oxidised cementite and former cracks. While the formation of numerous cracks, which are progressively filled with new oxides, can create areas in the dense corrosion products that exhibit no ghost structures, the structures are nevertheless always present on both sides 

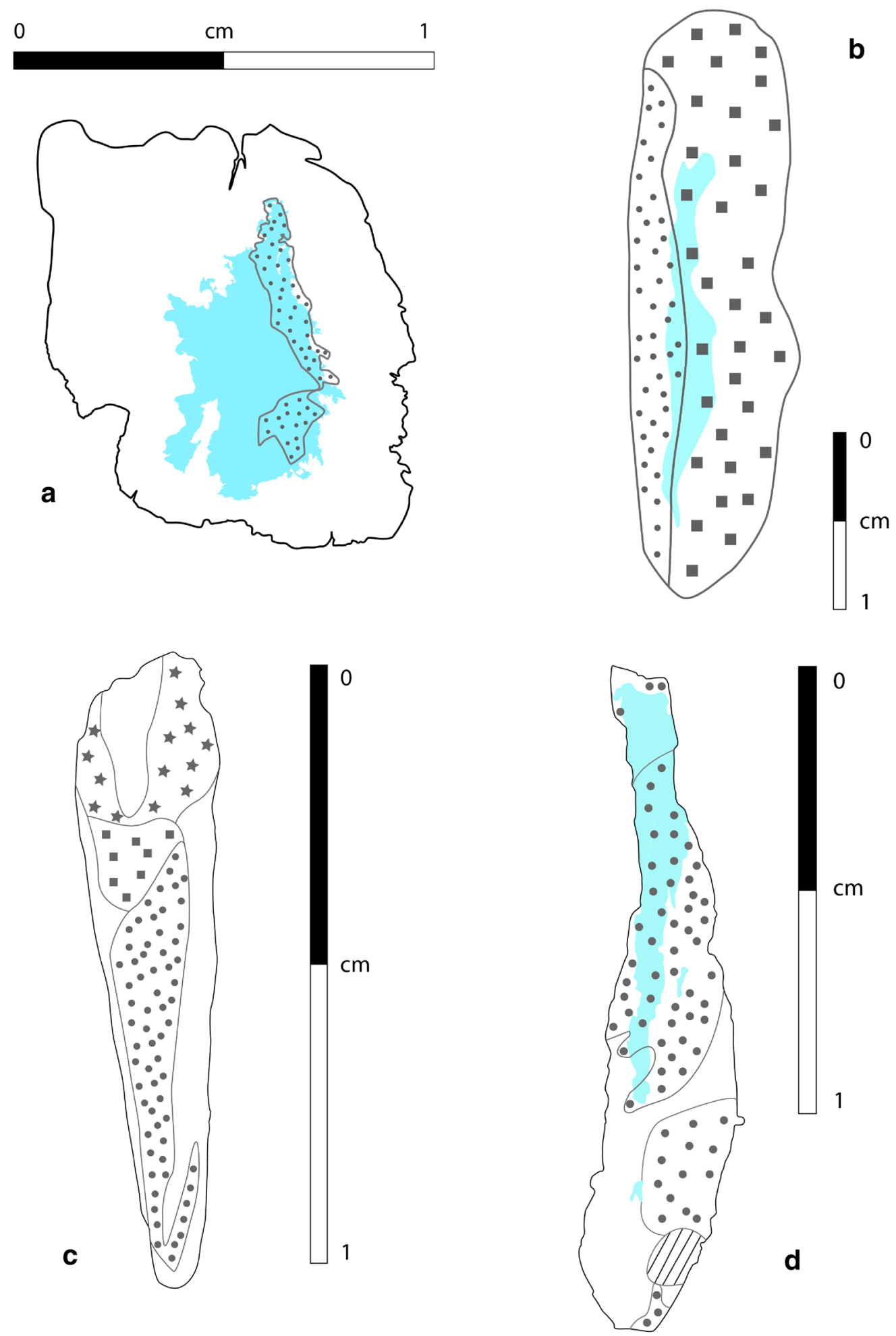
(See figure on previous page.)

Fig. 11 Illustration of mapping of ghost structures (graphitised and intact cementite in DPL) and structures revealed after nital etching (when possible) in a object \#1, b object \#2, c object \#3 and $\mathbf{d}$ object \#4. In blue: metallic part. a region with circles corresponds to lamellar pearlite in hypoeutectoid steel $(C<0,1 \%)$; region without circle has not reveal pearlitic structure. $\mathbf{b}$ region with squares corresponds to lamellar pearlite in hypereutectoid steel $(C \approx 1 \%)$; region with circles correspond to lamellar pearlite in close to eutectoid steel $(C \approx 0.78 \%)$; region without circle or square has not reveal pearlitic structure. $\mathbf{c}$ Region with circles corresponds to lamellar pearlite in hypoeutectoid steel $(C \approx 0.6 \%)$; region with squares corresponds to acicular overheat pearlite in hypoeutectoid steel $(C \approx 0.3-0.6 \%)$; region with stars corresponds to acicular overheat pearlite in hypoeutectoid steel $(C \approx 0.4 \%)$; region without circle, square or star has not reveal pearlitic structure. $\mathbf{d}$ region with circles corresponds to lamellar pearlite in hypoeutectoid steel (max. $0.2 \%$ C); region without circle has not reveal pearlitic structure; hatched region unreadable

of a crack, making the reconstruction of microstructure possible.

After etching in nital (where possible) and the mapping of ghost structures, non-oxidised cementite and former cracks in the four objects examined in this study showed that objects \#1, \#3 and \#4 (Fig. 11a, c, d) were composed of heterogeneous hypoeutectoid steel, while object \#2 was made up of one part hypereutectoid steel and one part eutectoid, or close to eutectoid, steel (Fig. 11b).

In objects \#1 (Fig. 12a), \#3 (Fig. 12d, e) and \#4 (Fig. 8d), the pearlite was always lamellar. This structure is appropriate for a tool, because lamellar pearlite is harder and less deformable than globular pearlite [40]. In object \#2 (Fig. 12b, c), lamellar pearlite was detected most of the time, but sometimes cementite in the process of spheroidisation was observed. Globular (or spheroid) cementite is obtained after long annealing [40, 41] and could be appropriate for hypereutectoid steel because of the diminution of the strength induced by the spheroidisation.

In addition, cementite needles or cementite grain boundaries could be observed in object \#2 (Fig. 12b). Cementite needles have been observed in other studies $[4,44]$ and can be formed after the precipitation of proeutectoid cementite (brittle) on austenitic grains boundaries during manufacturing processes $[4,42]$. The numerous clusters of cementite needles observed at high spatial resolution, which are formed by the diffusion of carbon during the ageing process [43], did not correspond to our object. Finally, acicular overheat structures, which reduce ductility and toughness [45], were observed in an area of object \#3 (Figs. 11c and 12e).

The results of this study are in line with those for Catalonian objects [1], which belong to the same sociocultural area as objects \#3 and \#4. The use of steel with heterogeneous composition and sometimes with overheat structures is an indication that the properties of the material were fit for purpose. Furthermore, the first iron alloy knives from the early Iron Age, including objects \#3 and \#4, located in the area between the Rivers Rhône (France) and Ebro (Spain) were mainly discovered in necropolises as funeral offerings. In addition, the typological influence on these knives was possibly eastern [46]. Hence, the presence of brittle or deformable structures, their function as a funeral offering and the possible eastern influence could mean that the knives had a more symbolic than functional value. It is also possible to propose some interpretations regarding objects \#1 and \#2, which were found in a Corsican habitat. Object \#1 (shaft easily workable) could have been some kind of semi-product, and object \#2 (very brittle) may have been a manufacturing failure.

\section{Conclusions}

Four objects from the first half of the early Iron Age were investigated using OM, FE-SEM/EDS/EBSD, XRD and micro-Raman spectroscopy. The following conclusions can be drawn:

(1) Dense corrosion products formed during the soil corrosion of objects are always composed of goethite, magnetite (the two main compounds) and lepidocrocite (small amount). In this study, other compounds were detected (including akageneite, maghemite, ferrihydrite, hematite and siderite) but not systematically.

(2) Soil corrosion mechanisms depend on an object's microstructure. It is proposed that random grain boundaries provide a preferential pathway for oxygen penetration and oxidation. Soil corrosion can also be driven locally by galvanic coupling between ferrite and cementite $\left(\mathrm{Fe}_{3} \mathrm{C}\right.$, enriched in carbon).

(3) At a certain stage of corrosion, cracks are formed in the dense corrosion products, providing new pathways for soil penetration. It was shown that a new oxide grows in the cracks due to the diffusion of iron ions through the dense product layer until obstruction occurs. The ghost microstructures on either side of the cracks are not affected by the formation of this new oxide.

(4) For the time being, this study provides experimental evidence of the graphitisation process and the formation of amorphous carbon. In both these processes, either cementite decomposes in ferrite (which is oxidised, as mentioned above), graphite and amorphous carbon or there is direct oxidation of Fe to iron oxide/oxyhydroxide. The rates of both processes can change over time 

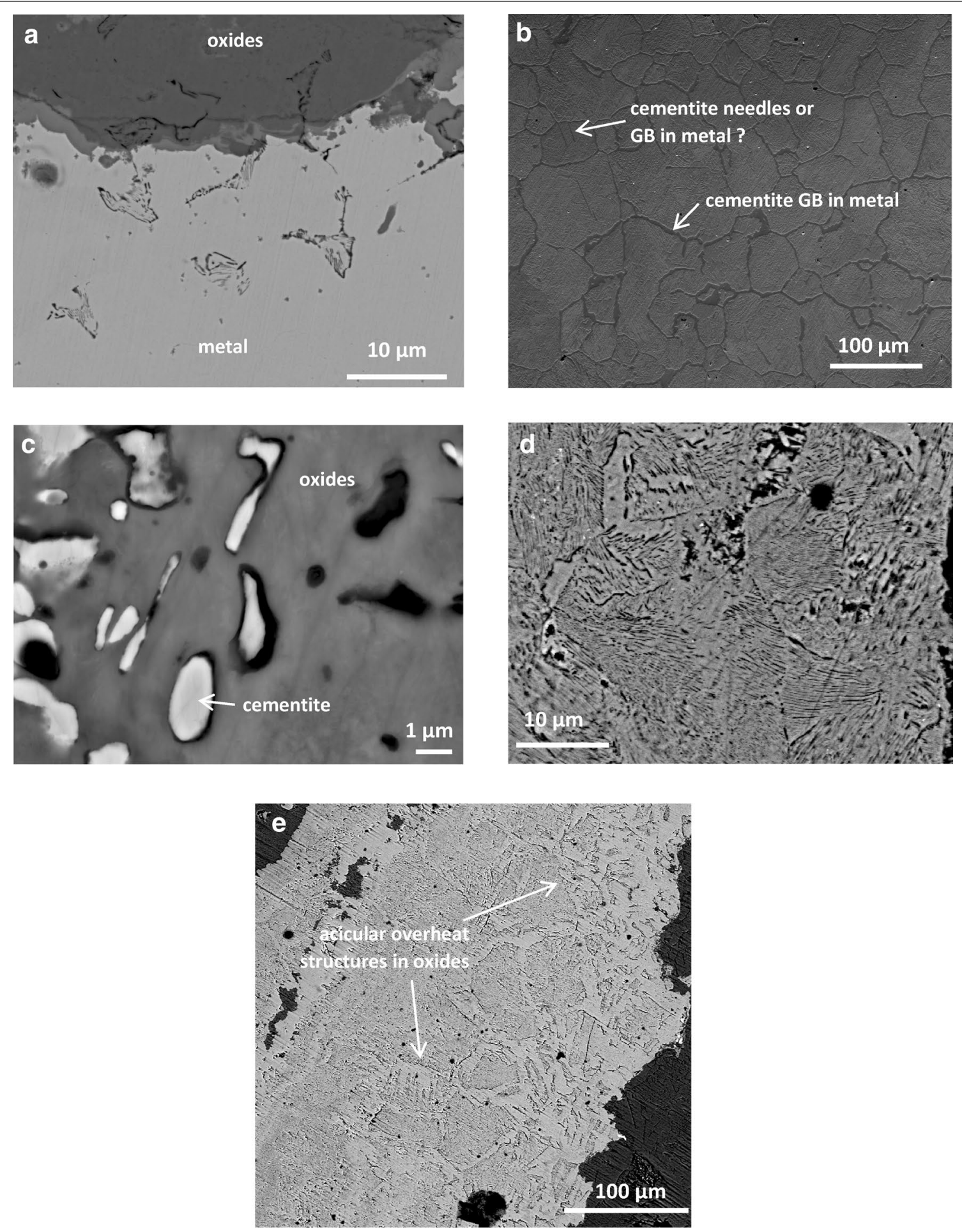

Fig. 12 FE-SEM micrographs of example of microstructures of a object \#1, b, c object \#2, d, e object \#3. a Lamellar pearlite in hypoeutectoid steel, b hypereutectoid steel, $\mathbf{c}$ globular cementite, $\mathbf{d}$ graphitised lamellar pearlitic structures, e acicular overheat structures 
according to environmental conditions (e.g. supply of oxygen). Graphite and amorphous carbon make up the ghost structures.

(5) The pearlitic structures of ancient iron alloys are observable until the destruction/decomposition of the items because of the stability of the graphite that makes up the structure during the last stage in the transformation of the cementite.

\section{Supplementary information}

Supplementary information accompanies this paper at https://doi. org/10.1186/s40494-020-00398-9.

Additional file 1. Raman spectra results for object \#2: (a) zone A; (b) zone B. Raman spectra results for object \#4: (c) zone A, (d) zone B. The zones are indicated in Fig. 2. $G=$ goethite, $H=$ hematite, $M t=$ magnetite, $L=$ lepidocrocite, $A=$ akaganeite.

Additional file 2. Raman spectra results for object \#3. (a) zone A, (b) zone B, (c) zone C and (d) zone D. The zones are indicated in Fig. 2. G= goethite, $\mathrm{H}=$ hematite, $\mathrm{Mt}=$ magnetite, $\mathrm{L}=$ lepidocrocite, $\mathrm{A}=$ akaganeite, $\mathrm{S}=$ siderite, $\mathrm{F}=$ ferrihydrite.

\section{Abbreviations}

CSL: Coincidence site lattice; EDS: Energy-dispersive spectroscopy; EBSD: Electron backscatter diffraction; FE-SEM: Field-emission scanning electron microscopy; GB: Grain boundary; GOS: Grain orientation spread; LABE: Low angle backscatter electron; OM: Optical microscopy; XRD: X-ray diffraction.

\section{Acknowledgements}

We thank Nicolas Geoffroy for assistance with XRD and Frederic Herbst for assistance with FE-SEM.

\section{Authors' contributions}

ALG and $\mathrm{V}$ wrote this article and interpreted the results (major contributors in writing the manuscript). HK and PO analysed objects with the micro Raman and interpreted the micro Raman results. HK also participated to discussions about corrosion mechanisms. KPQ gave the data of Corsican objects (dating and context) and allowed us to practice analysis. AR gave the data of the object from Le Causse (dating, picture and context) and allowed us to practice analysis. FM gave the data of the object from La Rouquette (dating, picture and context) and allowed us to practice analysis. All authors read and approved the final manuscript.

\section{Funding information}

This study was conducted within the framework of LabEx ARCHIMEDE and was supported by the "Investissement d'Avenir" programme (ANR-11LABX-0032-01, Agence Nationale de la Recherche, France). Publication fees were supported by ICB, UMR 6303 CNRS-Université de Bourgogne-Franche Comté (France).

\section{Data availability}

All data generated or analysed during this study are included in this article.

\section{Competing interests}

The authors declare that they have no known competing financial interests or personal relationships that could have appeared to influence the work reported in this paper.

\section{Author details}

${ }^{1}$ ASM-Archéologie des Sociétés Méditerranéennes, UMR 5140/Labex ARCHIMEDE, Programme IA ANR-11, Université Paul-Valéry Montpellier 3, Route de Mende, Site Saint-Charles, 34000 Montpellier, France. ${ }^{2}$ ICB, UMR 6303, CNRSUniversité de Bourgogne Franche Comté, BP 47870, Dijon Cedex, France.

${ }^{3}$ Faculty of Foundry Engineering, AGH University of Science and Technology,

Ul. Reymonta 23, 30-059 Krakow, Poland. ${ }^{4}$ Institute of Metallurgy and Materials
Science, Polish Academy of Sciences, 25 Reymonta Street, 30-059 Krakow, Poland. ${ }^{5}$ Inrap Méditerranée, Nîmes, France. ${ }^{6}$ ASM-Archéologie des Sociétés Méditerranéennes, UMR 5140, Montpellier, France. ${ }^{7}$ Mosaïques Archéologie, Cournonterral, France.

Received: 5 February 2020 Accepted: 30 May 2020

Published online: 17 June 2020

\section{References}

1. Rovira Hortalà C. Tecnología de las primeras manufacturas férricas en el nordeste de la Peninsula Ibérica-First iron technology in northern Iberian Peninsula. In: Rovira Llorens S, García-Heras M, Gener Moret M, Montero Ruiz I, editors. Actes del VII Congreso Ibérico de arqueometría. Madrid: CSIC; 2008. p. 458-67.

2. Renzi M, Rovira S, Rovira-Hortalà MC, Montero Ruiz I. Questioning research on early iron in the Mediterranean. In: Humphris J, Rehren T, editors. World of Iron. London: Archetype; 2013. p. 178-87.

3. Stepanov I, Weeks L, Franke K, Cable C, Overlaet B, Magee P, Händel M, Al Aali Y, Radwan M, Zein H. Methodologies for the investigation of corroded iron objects: examples from prehistoric sites in South-eastern Arabia and Western Iran. Sci Technol Archaeol Res. 2018. https://doi. org/10.1080/20548923.2018.1424304.

4. Eliyahu-Behar A, Yahalom-Mack N. Reevaluating early iron-working skills in the Southern Levant through microstructure analysis. J Archaeol Sci Rep. 2018. https://doi.org/10.1016/j.jasrep.2018.01.040.

5. Kaufmann B, Docter R, Fischer C, Chelbi F, Maraoui Telmini B. Ferrous metallurgy from the Bir Massouda metallurgical precinct at Phoenician and Punic Carthage and the beginning of the North African Iron Age. J Archaeol Sci. 2016. https://doi.org/10.1016/j.jas.2016.04.002.

6. Knox R. Detection of iron carbide structure in the oxide remains of ancient steel. Archaeometry. 1963. https://doi. org/10.1111/j.1475-4754.1963.tb00578.x.

7. Monnier J, Neff D, Réguer S, Dillmann P, Bellot-Gurlet L, Leroy E, Foy E, Legrand L, Guillot I. A corrosion study of the ferrous medieval reinforcement of the Amiens cathedral. Phase characterisation and localisation by various microprobes techniques. Corros Sci. 2010. https://doi. org/10.1016/j.corsci.2009.10.028.

8. Rémazeilles C, Neff D, Bourdoiseau JA, Sabot R, Jeannin M, Refait P. Role of previously formed corrosion product layers on sulfide-assisted corrosion of iron archaeological artefacts in soil. Corros Sci. 2017. https://doi. org/10.1016/j.corsci.2017.10.011.

9. Schneider A. Iron layer formation during cementite decomposition in carburising atmospheres. Corros Sci. 2002. https://doi.org/10.1016/S0010 $-938 \times(02) 00044-6$.

10. Pierson HO. Synthetic carbon and graphite: carbonization and graphitization. In: Pierson HO, editor. Handbook of Graphite, diamond, and fullerenes: Properties, Processing and Applications. Park Ridge: Noyes Publications; 1994. p. 70-86.

11. Bharadwaj M. Study of Graphitization in Carbon Steel Weldments for Remaining Life Assessment. Knoxville: Materials Science. PhD diss. University of Tennessee; 2016.

12. Reardon AC. Heat treatment of Steel. In: Reardon AC, editor. Metallurgy for non metallurgist. Materials Park: ASM International; 2011. p. 197-240.

13. Dillmann P, Balasubramaniam R, Beranger G. Characterization of protective rust on ancient Indian iron microprobe analyses. Corros Sci. 2002. https://doi.org/10.1016/S0010-938X(02)00028-8.

14. Dillmann P, Mazaudier F, Hoerlé S. Advances in understanding atmospheric corrosion of iron. I. Rust characterisation of ancient ferrous artefacts exposed to indoor atmospheric corrosion. Corros Sci. 2004. https:// doi.org/10.1016/j.corsci.2003.09.027.

15. Neff D, Dillmann P, Bellot-Gurlet L, Beranger G. Corrosion of iron archaeological artefacts in soil: characterisation of the corrosion system. Corros Sci. 2005. https://doi.org/10.1016/j.corsci.2004.05.029.

16. Hoerlé S, Mazaudier F, Dillmann P, Santarini G. Advances in understanding atmospheric corrosion of iron. II. Mechanistic modelling of wet-dry cycles. Corros Sci. 2004. https://doi.org/10.1016/j.corsci.2003.09.028.

17. Chitty WJ, Dillmann P, L'Hostis V, Lombard C. Long-term corrosion resistance of metallic reinforcement in concrete-a study of corrosion 
mechanisms based on archaeological artefacts. Corros Sci. 2007. https:// doi.org/10.1016/j.corsci.2004.07.032.

18. Réguer S, Dillmann P, Mirambet F. Buried iron archaeological artefacts: corrosion mechanisms related to the presence of $\mathrm{Cl}$-containing phases. Corros Sci. 2007. https://doi.org/10.1016/j.corsci.2006.11.009.

19. Demoulin A, Trigance C, Neff D, Froy E, Dillmann P, L'Hostis V. The evolution of the corrosion of iron in hydraulic binders analysed from 46- and 260-year-old buildings. Corros Sci. 2010. https://doi.org/10.1016/j.corsc i.2010.05.019

20. Mercier-Bion F, Li J, Lotz H, Tortech L, Neff D, Dillmann P. Electrical properties of iron corrosion layers formed in anoxic environments at the nanometer scale. Corros Sci. 2018. https://doi.org/10.1016/j.corsc i.2018.03.028.

21. Dillmann P, Béranger G, Piccardo P, Matthiessen H. Corrosion of metallic heritage artefacts: investigation, conservation and prediction of long term 48. Sawston: Woodhead Publishing; 2007.

22. Monnier J, Burger E, Berger P, Neff D, Guillot I, Dillmann P. Localisation of oxygen reduction sites in the case of iron long term atmospheric corrosion. Corros Sci. 2011. https://doi.org/10.1016/j.corsci.2011.04.002.

23. Saheb M, Neff D, Bataillon C, Foy E, Dillmann P. Copper tracing to determine the micrometric electronic properties of a thick ferrous corrosion layer formed in an anoxic medium. Corros Sci. 2011. https://doi. org/10.1016/j.corsci.2011.02.042.

24. Bellot-Gurlet L, Neff D, Réguer S, Monnier J, Saheb M, Dillmann P. Raman studies of corrosion layers formed on archaeological irons in various media. J. Nano RES-SW. 2009. https://doi.org/10.4028/www.scientific.net/ JNanoR.8.147.

25. Kassim J, Baird T, Fryer JR. Electron Microscope studies of iron corrosion products in water at room temperature. Corros Sci. 1982;22:147-58. https ://doi.org/10.1016/0010-938X(82)90075-0.

26. Kitick AA, Rublova YD, Kelm A, Malyshev W, Bannyck NG, Flis-Kabulska I. Kinetics and mechanism of corrosion of mild steel in new types of ionic liquids. J Electroanal Chem. 2018. https://doi.org/10.1016/j.jelec hem.2018.06.018.

27. Peche-Quilichini K, Bergerot L, Lachenal T, Martinetti D, Py V, Regert M. Les fouilles de Cuciurpula: la structure 1. In: Peche-Quilichini K, editor. L'âge du Fer en Corse. Acquis et perspectives. Actes de la Table-Ronde de Serra-diScopamena (7 août 2009). Serra-di-Scopamena: Associu Cuciurpula; 2012, p. 35-57.

28. Noth NA, Pearson C. Methods for Treating Marin Iron. ICOM, Commitee for Conservation, 5th Triennal Meeting, Zagreb, 1978. Rotterdam: International Council of Museums; 1978. p. 1-10.

29. Ortiz AL, Cumbrera FL, Sanchez-Bajo S, Guiberteau F, Caruso R. Fundamental parameters approach in the Rietveld method: a study of the stability of results versus the accuracy of the instrumental profile. J Eur Ceram Soc. 2000. https://doi.org/10.1016/S0955-2219(00)00056-X.

30. Hanesch M. Raman spectroscopy of iron oxides and (oxy)hydroxides at low laser power and possible applications in environmental magnetic studies. Geophys J Int. 2009. https://doi.org/10.1111/j.1365246X.2009.04122.x.

31. Oh SJ, Cook DC, Townsend HE. Characterization of iron oxides commonly formed as corrosion products on steel. Hyperfine Interact. 1998. https:// doi.org/10.1023/A:1011076308501.

32. University of Arizona, 2019. RRUFF database: Goethite R120086.

33. Jacintho GVM, Corio P, Rubim JC. Surface-enhanced Raman spectra of magnetic nanoparticles adsorbed on a silver electrode. J Electroanal Chem. 2007. https://doi.org/10.1016/j.jelechem.2007.02.019.

34. de Faria DLA, Venancio Silva S, de Oliveira MT. Raman microspectroscopy of some iron oxides and oxyhydroxides. J Raman Spectrosc. 1997. https ://doi.org/10.1002/(SICI)1097-4555(199711)28:11\%3c873:AID-JRS17 7\%3e3.0.CO;2-B.
35. Shebanova ON, Lazor P. Raman spectroscopic study of magnetite $\left(\mathrm{FeFe}_{2} \mathrm{O}_{4}\right.$ ): a new assignment for the vibrational spectrum. I Solid State Chem. 2003. https://doi.org/10.1016/S0022-4596(03)00294-9.

36. Kokawa H, Shimada M, Sato YS. Grain-boundary structure and precipitation in sensitized austenitic stainless steel. JOM. 2000. https://doi. org/10.1007/s11837-000-0159-0.

37. Atkinson A. Grain boundary diffusion — structural effects and mechanisms. J de Phys. 1985. https://doi.org/10.1051/jphyscol:1985441.

38. Ferrari AC. Raman spectroscopy of graphene and graphite: disorder, electron-phonon coupling, doping and nonadiabatic effects. Solid State Commun. 2007. https://doi.org/10.1016/j.ssc.2007.03.052.

39. Cançado LG, Jorio A, Martins Ferreira EH, Stavale F, Achete CA, Capaz RB, Moutinho MVO, Lombardo A, Kulmala TS, Ferrari AC. Quantifying defects in graphene via Raman Spectroscopy at different excitation energies. Nano Lett. 2011. https://doi.org/10.1021/n|201432g.

40. Allain S, Roth A, Bouaziz O, D'Eramo E. Microstructure-based behavior law for globular pearlitic steels. J Mater Res Technol. 2019. https://doi. org/10.1016/j.jmrt.2019.03.014.

41. Gordon RB, Van der Merwe NJ. Metallographic study of iron artefacts from the eastern Transvaal, south Africa. Archaeometry. 1984. https://doi. org/10.1111/j.1475-4754.1984.tb00324.x.

42. Spanos G, Kral M. The proeutectoid cementite transformation in steels. Int Mater Rev. 2009. https://doi.org/10.1179/174328009X392949.

43. Munoz EB, Fernández JC, Arasanz JG, Peces RA, Criado AJ, Dietz C, Martínez JA, Portal AJC. Archaeologic analogues: microstructural changes by natural ageing in carbon steels. J Nucl Mater. 2006. https://doi. org/10.1016/j.jnucmat.2005.06.022.

44. Stepanov I, Weeks L, Salvemini F, Al Ali Y, Radwan MB, Zein H. Early iron age artefacts from southeastern Arabia: investigating fabrication techniques using neutron tomography, optical microscopy, and SEM-EDS. Archaeol Anthropol Sci. 2018. https://doi.org/10.1007/s1252 0-018-0730-7.

45. Colpaert H. Metallography of steels. Interpretation of structure and the effects of Processing. Materials Park: ASM International; 2018.

46. Grevey AL, Gailledrat E. The origins of the first ferrous knives on the Iberian Peninsula and in Southern France: a typological viewpoint (9th-7th centuries BC). In: Belarte MC, Rovira MC, Sanmartí J, editors. Iron metallurgy and the formation of complex societies in the Western Mediterranean (1st millennium BC): Proceedings of the 8th International Achaeological Meeting of Calafell (Calafell, from 6th to 8th October 2016). Barcelona: University of Barcelona; 2020, p. 115-124.

\section{Publisher's Note}

Springer Nature remains neutral with regard to jurisdictional claims in published maps and institutional affiliations.

\section{Submit your manuscript to a SpringerOpen ${ }^{\odot}$ journal and benefit from:}

- Convenient online submission

- Rigorous peer review

- Open access: articles freely available online

- High visibility within the field

- Retaining the copyright to your article

Submit your next manuscript at $\boldsymbol{\nabla}$ springeropen.com 